\title{
A 50-Year-Old Woman with Marfan's Syndrome
}

\author{
Shekhar Bhattacharjee ${ }^{1}$, Swapna Bhattacharjee ${ }^{2}$ \\ Received: August 14, 2012 Accepted: May 23, 2013
}

\begin{abstract}
Marfan syndrome (MFS) is a systemic connective tissue disorder. It is an autosomal dominant disorder caused by mutations in the extracellular matrix protein fibrillin-1 gene located on chromosome 15. It has variable range of expressions. Cardiovascular manifestations in Marfan's syndrome patients include aortic and valvular diseases. Here we describe a 50-yearold female patient with Marfan syndrome who had aortic aneurysm with mitral and aortic regurgitation. Diagnosis was made on the basis of physical examination, color doppler study and family screening. She was previously being treated as a case of rheumatic valvular disease because her body habitus was overlooked. She was managed conservatively and advised to go for prophylactic surgery to prevent aortic dissection. She was also counseled about screening her children for transmission and expression of this disease.
\end{abstract}

Key words: Marfan's syndrome, Aneurysm, Regurgitation

J Enam Med Col 2014; 4(1): 60-64

\section{Introduction}

Marfan syndrome (MFS) is an autosomal dominant (AD) inherited disorder of connective tissue. It is a multisystem disorder with manifestations typically involving the cardiovascular, skeletal and ocular systems. It occurs in all ethnic groups and has a prevalence of 1 in 100,000 population. ${ }^{1,2}$ In about $75 \%$ cases the defective gene on chromosome 15 is inherited $^{3}$ from an affected parent. However, in about $25 \%$ cases it is due to new mutation. The patient under discussion had cardiovascular features including aortic aneurysm with mitral and aortic regurgitation though marfanoid features were overlooked for a long time. The objective of reporting this case is to emphasize the importance of physical examination after proper exposure to look for skeletal features in patients with aortic regurgitation with or without mitral regurgitation, specially in context of conservative rural Bangladeshi female patients.

\section{Case report}

A 50-year-old non-smoker, non-diabetic, normo- tensive housewife presented on $18^{\text {th }}$ February 2011 with shortness of breath on exertion and palpitation for one year. She did not give any history suggestive of rheumatic fever or any connective tissue disorder. She denied any form of sexual promiscuity in her life. On examination, she was breathless on mild exertion but neither cyanosed nor clubbed, her blood pressure (BP) was $140 / 30 \mathrm{~mm} \mathrm{Hg}$, pulse was 80 beats/min and regular in rhythm and respiratory rate was $22 / \mathrm{min}$. Her jugular venous pressure was not raised. Precordium examination revealed a thrusting apical impulse at $5^{\text {th }}$ intercostal space just lateral to the left midclavicular line. Both $1^{\text {st }}$ and $2^{\text {nd }}$ heart sounds were soft and there was no third or fourth heart sound. A prominent early diastolic murmur was heard along left sternal edge with patient leaning forward and breath held in expiration and there was a pansystolic murmur in the mitral area radiating to left axilla. Examination of other systems did not reveal any abnormalities.

1. Professor, Department of Medicine, Shahabuddin Medical College \& Hospital, Dhaka

2. Professor, Department of Medicine, Shahabuddin Medical College \& Hospital, Dhaka

Correspondence Shekhar Bhattacharjee,Email: shbhattacharjee07@yahoo.com 


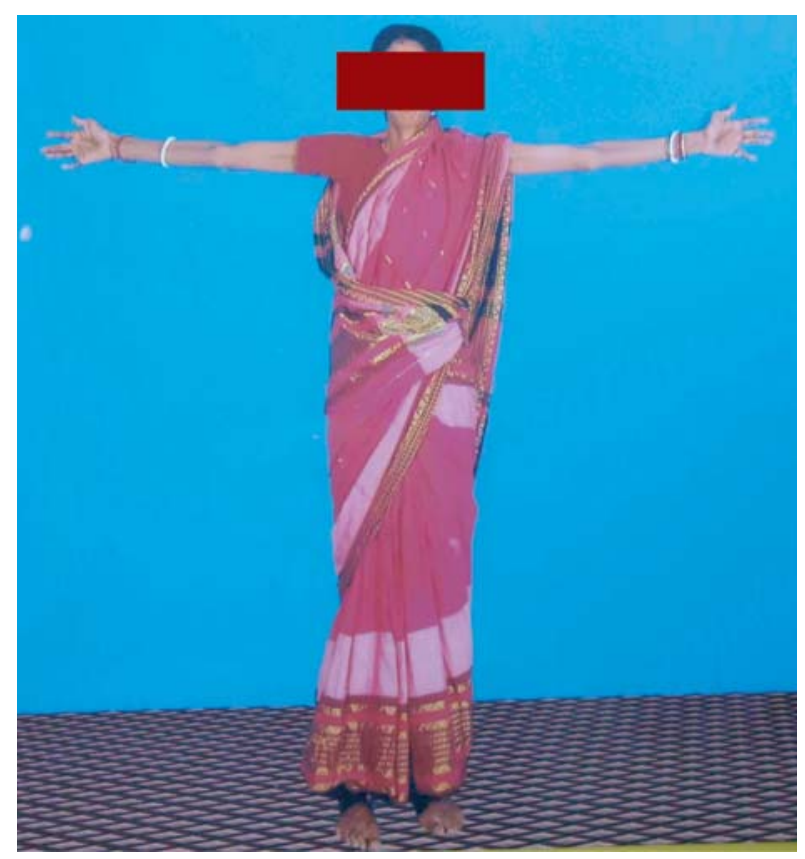

Fig 1

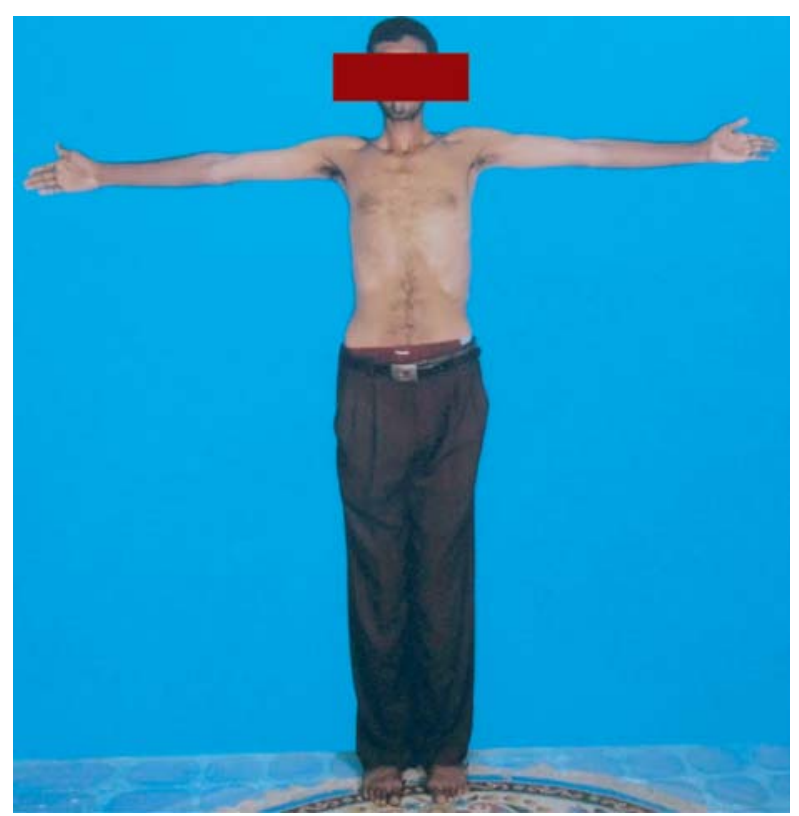

Fig 2

The patient was previously diagnosed as a case of rheumatic heart disease with combined aortic and mitral regurgitation and was treated with digoxin, diuretic and benzathine penicillin injection monthly as prescribed from a cardiac institute. As she used to wear traditional dress (long clothes) around her body, her physical appearance and body habitus could easily be overlooked. After proper exposure her height and arm span (Fig 1) were recorded 5'6" and 5' 8 " respectively. She had high arched palate, mild scoliosis, flat feet and arachnodactyly with positive thumb sign. Her family members were screened by physical examination and her son was found to have marfanoid features (Fig 2) with faint aortic regurgitant murmur. Electrocardiogram (ECG) showed sinus tachycardia with borderline left ventricular hypertrophy. Color doppler study showed grade III aortic regurgitation and grade II mitral regurgitation. All the chambers were normal. Mitral valve was normal in appearance. Aortic valve cusps were normal with normal systolic opening. Ascending aorta was hugely dilated $(60 \mathrm{~mm})$. Left ventricular systolic function was fair with ejection fraction $52 \%$.

Complete blood count, urine routine examination, serum creatinine, random blood sugar and antistreptolysin $\mathrm{O}$ were normal. Rheumatoid factor, venereal disease research laboratory (VDRL) and Trepenoma pallidum hemaglutinaiton (TPHA) tests were negative. Chest radiography was unremarkable. Special tests including slit lamp examination of eyes and genetic testing could not be done due to limited resources.

\section{Treatment}

The patient was advised to take rest. She was prescribed salt restriction, $\beta$ blocker and low dose angiotensin converting enzyme inhibitor (ACEI). After about three weeks she was found marginally better. She was given prophylaxis for infective endocarditis. Considering the aortic diameter she was advised to come for regular follow-up at cardiac center and counseled about prophylactic surgery on aortic root and ascending aorta with the aim of avoiding mortality associated with type A aortic dissection. As her son was found to have marfanoid features along with faint aortic regurgitant murmur, she was suggested for screening of other family members to receive genetic counseling and prophylactic treatment, if necessary.

\section{Discussion}

MFS is an autosomal dominant disorder of fibrous tissue due to mutation of fibrillin gene located on chromosome 15 . The condition classically involves skeletal, ocular and cardiovascular systems in addition to skin, pulmonary and neurological complications. About $90 \%$ of patients with Marfan's syndrome will develop cardiac complications. ${ }^{2}$ 
Following the development of molecular detection of defective fibrillin gene (FBNI), diagnostic criteria for Marfan's syndrome as proposed by de Paepe et $\mathrm{al}^{4}$ revising the previous Berlin criteria were followed. For diagnosing MFS, the subject being examined must have a first-degree relative affected with the disease and involvement of two systems with a major sign. In absence of genetic criteria, there should be involvement of three systems, at least two with major signs.

In addition to routine chest radiography and ECG, echocardiography is considered. Several reports have documented the accuracy and usefulness of echocardiography in the detection of aortic root dissection or dilatation or both ${ }^{5}$ which is particularly useful in deciding whether cardiac surgery should be performed or avoided. ${ }^{6}$

\section{Management}

The diagnosis, follow-up plan and treatment strategy for MFS require a multidisciplinary team which should include geneticist, ophthalmologist, cardiologist and orthopedic surgeon.

Ectopia lentis, which can lead to glaucoma, is a major diagnostic criterion of MFS. There may be retinal detachment and cataract. Yearly assessment by an ophthalmologist is essential. Severe scoliosis often requires surgical stabilization. In many patients, pectus deformity causes restrictive lung disease. A recent report described a significant increase in forced vital capacity after surgery with improvement most prominent in patients over 11 years of age. ${ }^{7}$

Given its impact on prognosis, the monitoring of patients with MFS is mainly directed toward the control of aortic disease. Treatment of patients with MFS with aortic involvement rests on following three main strategies: pharmacological treatment, prophylactic aortic surgery and advice about change in lifestyle.

\section{Pharmacologic treatment}

$\beta$ blocker: Various retrospective studies have shown important role of $\beta$ blocker in prevention of progression of aortic dilatation in patients with MFS $^{8,9}$ which is attributed to reduction of aortic wall stress by negative chronotropic and inotropic effects. ${ }^{10}$ Current recommendation advises early use of $\beta$ blocker in all patients with MFS independent of aortic diameter. ${ }^{11}$
Renin-angiotensin system blocker: Over past few years, role of renin angiotensin system in pathogenesis of aortic dilatation has been growing. ${ }^{12}$ The beneficial effect with treatment of ACEI is attributed to control of $\mathrm{BP}$ and reduction of stiffness of aortic wall ${ }^{12}$ though its molecular mechanism is independent of control of BP. ${ }^{13}$

Doxycycline: A small dose of doxycycline which inhibits protease has been shown to prevent fragmentation of elastic fiber and prevents aortic rupture in mice model. ${ }^{14}$ Though not formally tested in aortic aneurysm, its use has shown beneficial effect. ${ }^{15}$

Prophylactic surgery on aorta: To avoid mortality associated with type A aortic dissection, prophylactic surgery on aortic root has the greatest therapeutic impact on survival of patients with MFS. ${ }^{16}$ Risk correlates positively with aortic diameter and therefore elective surgery is recommended when ascending aortic diameter is greater than $50 \mathrm{~mm}$ or even earlier if other risk factors are present. ${ }^{17}$ To avoid anticoagulant related risks, replacement of aortic root with preservation of aortic valve, if normal, is the present technique. ${ }^{18}$ Close monitoring and $\beta$ blocker are continued after surgical repair in all patients. ${ }^{11}$ For mitral valve prolapse (MVP), surgical repair is preferred if technically feasible ${ }^{19}$ avoiding long term risk of anticoagulation.

Endocarditis prophylaxis: National Marfan Foundation advocates use of endocarditis prophylaxis for patients with MFS who have valvular regurgitation. ${ }^{20}$

Obstetric complication and treatment: During pregnancy, there is extra load on cardiovascular system and in MFS patients, heart failure may be precipitated. ${ }^{21}$ There is increased risk of aortic type A dissection typically in 3rd trimester and associated with high fetal mortality and with maternal mortality of around $50 \% .{ }^{21}$ Nevertheless, according to the European Society of Cardiology pregnancy is not contraindicated in patients with an aortic root diameter of $<40$ $\mathrm{mm} .{ }^{22}$ Patients with an aortic diameter $\geqslant 40 \mathrm{~mm}$ who wish to have children are recommended to undergo elective aortic replacement surgery. ${ }^{22}$ 
Advice about lifestyle: As physical exercise increases the stress on the wall of the aorta which can contribute to aortic dissection, strenuous exercise should be avoided. ${ }^{23}$

Genetic counseling: As MFS is an AD disease, couples with one affected partner have a $50 \%$ risk of transmission to offspring which should be explained to affected patient. Preimplantation diagnosis ${ }^{21,24}$ or prenatal diagnosis ${ }^{21}$ with therapeutic abortion are important options that can prevent transmission of this condition.

\section{Prognosis}

The first long-term survival study by Murdoch ${ }^{25}$ in 1972 on MFS patients who did not undergo aortic surgery showed that mean age of death was 32 years and $90 \%$ of all deaths resulted from cardiovascular causes $^{2}$ of which aortic rupture was responsible for $80 \%$. However, with earlier diagnosis, better medical management and introduction of prophylactic aortic repair surgery, life expectancy has greatly increased by several decades and approaching to that of general population. ${ }^{26}$

\section{Conclusion}

Although rheumatic fever is still the most common cause of aortic and mitral regurgitation in Bangladesh, the presence of pure regurgitant murmur demands complete physical examination of the patient to look for marfanoid features so that proper management including family screening may be offered to the patient before it is too late. Furthermore, there is an active area for more trials and research to improve pharmacological treatment to delay aortic aneurysmal progression in these patients.

\section{Consent}

Written informed consent was obtained from the patient for publication of the case report with accompanying pictures.

\section{References}

1. Majid A, Khan MA, Shah PA, Bhat MY, Lanker SS. JKPractitioner 2002; 9(4): 256-257.

2. National Marfan Foundation, Port Washington, NY, 11050, 1-800-8-MARFAN (516) 883-8712. Available at: http.www. marfan. org. Accessed March 2013.
3. McKusick VA. Marfan syndrome: Mendelian inheritance in man. Available at: http://www3.ncbi.nlm.nih.gov. Accessed March 2013.

4. De Paepe A, Devereux RB, Dietz HC, Hennekam RC, Pyeritz RE. Revised diagnostic criteria for the Marfan's syndrome. Am J Med Genet 1996; 62: 417-426.

5. Nanda NC, Gramiak R, Shah PM. Diagnosis of aortic root dissection by echocardiography. Circulation 1973; 48: 503 .

6. Moothart RW, Spangler RD, Blount SG. Echocardiography in aortic root dissection and dilatation. Am Cardiol 1975; 36: 11 .

7. Lawson ML, Mellins RB, Tabangin M, Kelly RE Jr, Croitoru DP, Goretsky MJ et al. Impact of pectus excavatum on pulmonary function before and after repair with the nuss procedure. J Paed Surgery 2005; 40: 174-180.

8. Gersony O, McClaughlin R, Jin ZMA, Gersony WM. The effect of beta-blocker therapy on clinical outcome in patients with Marfan's syndrome: a meta-analysis. Int J Cardiol 2007; 114: 303-308.

9. Shores J, Berger KR, Murphy EA, Pyeritz RE. Progression of aortic dilatation and the benefit of long term beta-adrenergic blockade in Marfan's syndrome. $\mathrm{N}$ Engl J Med 1994; 330: 1335-1341.

10. Haouzi A, Berglund H, Pelikan PC, Maurer G, Siegei RJ. Heterogeneous aortic response to acute beta-adrenergic blockade in Marfan syndrome. Am Heart J 1997; 133: $60-63$.

11. Keane MG, Pyeritz RE. Medical management of Marfan syndrome. Circulation 2008; 117: 2802-2813.

12. Vetman AT, Bornemeier RA, McCrindle BW. Usefulness of enalapril versus propranolol or atenolol for prevention of aortic dilation in patients with the Marfan syndrome. Am J Cardio 2005; 95: 1125-1127.

13. Matt P, Habashi J, Carrel T, Cameron DE, Van Eyk JE, Dietz $\mathrm{HC}$ et al. Recent advances in understanding Marfan syndrome: should we now treat surgical patients with losartan? J Thorac Cardiovasc Surg 2008; 135: 389-394.

14. Xiong W, Knispel RA, Dietz HC, Ramirez F, Baxter BT. Doxycycline delays aneurysm rupture in a mouse model of Marfan syndrome. J Vasc Surg 2008; 47: 166-172.

15. Abdul-Hussien H, Hanemaaijer R, Verheijen JH, van Bockel JH, Geelkerken RH, Lindeman JH. Doxycycline therapy for abdominal aneurysm: improved proteolytic balance through reduced neutrophil content. J Vasc Surg 2009; 49: 741-749.

16. Gott VL, Greene PS, Alejo DE, Cameron DE, Naftel DC, Miller DC et al. Replacement of the aortic root in 
patients with Marfan's syndrome. N Engl J Med 1999; 340: 1307-1313.

17. Pearson GD, Devereux R, Loeys B, Maslen C, Milewicz D, Pyeritz R et al. Report of the National Heart, Lung and Blood Institute and National Marfan Foundation Working Group on Research in Marfan Syndrome and Related Disorders. Circulation 2008; 118: 785-791.

18. David TE, Armstrong S, Maganti M, Colman J, Bradley TJ. Long-term results of aortic valve-sparing operations in patients with Marfan syndrome. J Thorac Cardiovasc Surg 2009; 138: 859-864.

19. Bhudia SK,Troughton R, Lam BK, Rajeswaran J, Mills WR, Gillinov AM et al. Mitral valve surgery in the adult Marfan syndrome patient. Ann Thorac Surg 2006; 81: 843-848.

20. National Marfan Foundation NMF PAB Endocarditis Prophylaxis Guidelines, 2007. Available at: http://www.marfan.org/marfan/2565/NMF-PABEndocarditis.-Prophylaxis.-Guidelines/2007(2007). Accessed April 2013

21. Lalchandani S, Wingfield M. Pregnancy in women with
Marfan's syndrome. Eur. J. Obstet. Gynecol. Reprod. Biol. 2003; 110: 125-130.

22. The Joint Task Force on the Management of Valvular Heart Disease of the European Society of Cardiology (ESC) and the European Association for CardioThoracic Surgery (EACTS). Guidelines on the management of valvular heart disease: the task force on the management of valvular heart disease of the European Society of Cardiology. Eur Heart J 2007; 28: 230-268.

23. Maron BJ, Chaitman BR, Ackerman MJ, Bayés de Luna A, Corrado D, Crosson JE. Recommendations for physical activity and recreational sports participation for young patients with genetic cardiovascular diseases. Circulation 2004; 109: 2807-2816.

24. Lledo B, Ten J, Galan FM, Bernabeu R. Preimplantation genetic diagnosis of Marfan syndrome using multiple displacement amplification. Fertil. Steril. 2006; 86: 949-955.

25. Finkbohner R, Johnston D, Crawford ES, Coselli J, Milewicz DM. Marfan syndrome. Long-term survival and complications after aortic aneurysm repair. Circulation 1995; 91: 728-733. 